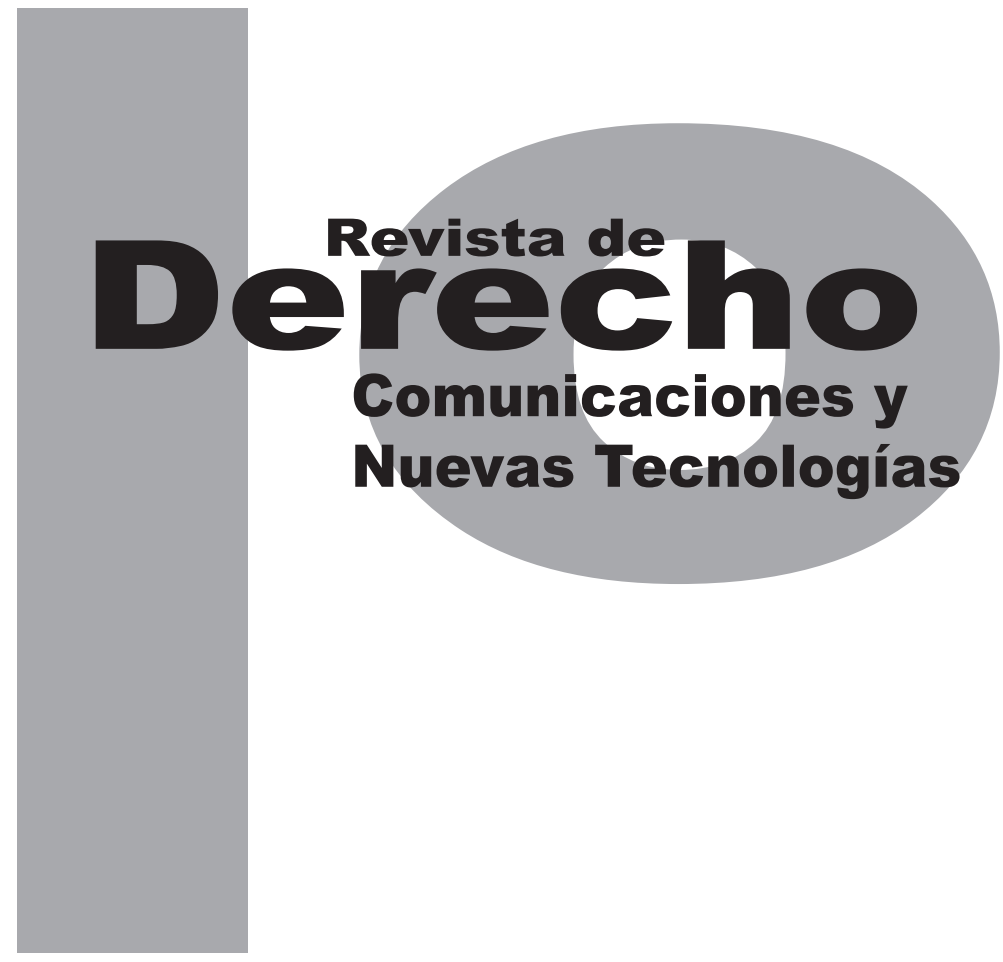

\title{
LA EQUIVALENCIA FUNCIONAL EN EL DOCUMENTO DE TRANSPORTE ELECTRÓNICO (REGLAS DE ROTTERDAM)
}

\author{
René CANo ARIZa
}

Artículo de reflexión

DOI: http://dx.doi.org/10.15425/redecom.12.2014.15

Universidad de los Andes

Facultad de Derecho

Revista de Derecho, Comunicaciones y Nuevas Tecnologías

No.12, Julio - Diciembre de 2014. ISSN 1909-7786 


\section{La equivalencia funcional en el documento de transporte electrónico (Reglas de Rotterdam)}

\section{Resumen}

El presente artículo tiene como propósito abordar los problemas relativos a la equivalencia funcional y las consecuencias en la desincorporación de los títulos representativos de mercancías mediante soporte electrónico, así como su regulación en las Reglas de Rotterdam a través del documento de transporte electrónico. Se hace un breve análisis sobre el principio de equivalencia funcional sobre la garantía de singularidad y la transferencia de control del documento electrónico que el Grupo de Trabajo IV sobre comercio electrónico de la CNUDMI ha venido elaborando en recientes sesiones.

Palabras clave: comunicaciones electrónicas, derecho documentado, desmaterialización, desincorporación, equivalencia funcional, ejemplar fehaciente, garantía de singularidad, Reglas de Rotterdam, transferencia de control, título-valor, transporte marítimo de mercancías, unicidad.

\section{Functional equivalence in electronic transport document (Rules of Rotterdam)}

\section{Abstract}

This article aims to address the problems of functional equivalence and consequences in the divestiture of title to goods by electronic media and its regulation in the Rotterdam Rules through the electron transport document. A brief analysis of the principle of functional equivalence on the uniqueness and guarantee the transfer of control of the electronic document to the Working Group on electronic commerce IV UNCITRAL has been developed in recent sessions ago.

Keywords: electronic communications, documented law, dematerialization, disincorporation, functional equivalence, reliable copy, guarantee uniqueness, Rotterdam Rules, transfer of control, negotiable instrument, freight shipping, uniqueness.

\section{A equivalência funcional no documento de transporte eletrônico (Regras de Rotterdam) Resumo}

O presente artigo tem como propósito abordar os problemas relativos com a equivalência funcional e as consequências na desincorporação dos títulos representativos de mercadorias mediante suporte eletrônico, assim como sua regulação nas Regras de Rotterdam através do documento de transporte eletrônico. É feita uma breve análise sobre o princípio de equivalência funcional sobre a garantia de singularidade e a transferência de controle do documento eletrônico que o Grupo de Trabalho IV, sobre comércio eletrônico da CNUDMI, tem vindo elaborando em sessões recentes.

Palavras-chave: comunicações eletrônicas, direito documentado, desmaterialização, desincorporação, equivalência funcional, exemplar fidedigno, garantia de singularidade, Regras de Rotterdam, transferência de controle, título-valor, transporte marítimo de mercadorias, unicidade. 


\title{
La equivalencia funcional en el documento de transporte electrónico (Reglas de Rotterdam)*
}

\author{
René Cano Ariza**
}

\section{SUMARIO}

Introducción - I. Regulación Jurídica Internacional del Conocimiento de Embarque - II. Desmaterialización del conocimiento de embarque y la electronificación del contrato de transporte - III. Convenio de las Naciones Unidas sobre el Contrato de Transporte Internacional de Mercancías Total o Parcialmente Marítimo. Reglas de Rotterdam de 2008 - IV. Equivalencia funcional en el empleo del documento de transporte electrónico - V. Procedimiento de transferencia del documento de transporte electrónico - VI. Conclusiones - Referencias.

\footnotetext{
* Cómo citar este artículo: Cano, R. (Diciembre, 2014). La equivalencia funcional en el documento de transporte electrónico (Reglas de Rotterdam). Revista de Derecho, Comunicaciones y Nuevas Tecnologías, 12. Universidad de los Andes (Colombia).

** Es abogado y notario adscrito en Orizaba. Ha fungido como profesor de los cursos Derecho Romano, Derecho de las Obligaciones y Contratos, Derecho Procesal Civil y Derecho Notarial en la Universidad del Valle de Orizaba (México). Doctorando en Derecho Patrimonial por la Universidad de Salamanca (España). Correo electrónico renecano63@hotmail.com.
} 
Introducción

La implementación de las nuevas tecnologías en el ámbito del derecho, en especial del cartular, ha generado la desmaterialización del títulovalor. Esta tendencia se acentuó internacionalmente mediante la elaboración de convenios internacionales que armonizan y unifican su regulación adecuándolo también al ámbito del derecho del transporte marítimo de mercaderías.

Así encontramos que el conocimiento de embarque como título representativo de las mercancías, llega a ser sustituido por el documento de transporte. Bajo esta concepción es acogido por la Comisión de Naciones Unidas para el Derecho Mercantil Internacional (CNUDMI) por medio del Convenio de las Naciones Unidas sobre el Contrato de Transporte Internacional de Mercaderías Total o Parcialmente Marítimo, también denominado "Reglas de Rotterdam" (en adelante RR).

En él se regula la emisión y transmisión del documento de transporte en soporte electrónico. Para lograrlo es imprescindible equiparar todos los presupuestos jurídicos de validez del soporte en papel del título-valor al electrónico: firma, literalidad (derecho incorporado al documento), abstracción, autonomía y circulación. Lo anterior se logra mediante la aplicación de los principios que rigen el comercio electrónico, teniendo como base el principio de equivalencia funcional.

Sin embargo, uno de los principales temas que se han discutido desde el punto de vista jurídico y tecnológico es el de identificar el "ejemplar fehaciente" del documento electrónico con características cambiarias diferenciándose de sus posibles copias, así como la posesión material y la transferencia de los derechos documentados en él mediante la simple entrega.

Para ello, el Grupo de Trabajo IV sobre el comercio electrónico (GT-IV) con apoyo a las legislaciones de Estados Unidos y de la República de Corea ha establecido la incorporación de los conceptos de "garantía de singularidad del documento electrónico" y la "transferencia del control del documento electrónico"; conceptos que también llegan ser aplicables en la transmisión del documento de transporte electrónico regulado por las RR.

\section{REGULACIÓN JURÍDICA DEL CONOCIMIENTO DE EMBARQUE}

La regulación jurídica del transporte bajo conocimiento de embarque tiene como principal objetivo la unificación de las reglas que han surgido de diversos y muy variados convenciones internacionales promulgados a intereses de los navieros y de los cargadores. Precisamente, será la empresa naviera a través de su superioridad económica la que ponga sus intereses por encima de las empresas cargadoras. Esos intereses se centraron en cláusulas de exoneración de la responsabilidad del porteador tan amplias que la confinaban a los casos de dolo.

El 25 de agosto de 1924 se aprobó el Convenio Internacional para la Unificación de Ciertas Reglas en Materia de Conocimiento de Embarque, 
o Convenio de Bruselas, también adoptado con

el nombre de Reglas de La Haya en honor a su texto original.

Este instrumento internacional fue ratificado por numerosos países entrando en vigor el 2 de junio de 1931. Contiene reglas o principios para regular el principal documento contractual del transporte que es el conocimiento de embarque haciendo a un lado la póliza de fletamento, salvo que se hubiese puesto en circulación regulando las relaciones entre su tenedor y el porteador. Respecto a su aplicación, el onvenio adopta un criterio territorial bajo el principio lex loci actus, puesto que el lugar de emisión del conocimiento servirá para delimitar el ámbito de aplicación de la convención.

Entre los principales objetivos que se consiguieron con el Convenio de Bruselas o Reglas de La Haya se encuentran (Espinoza, 1991, p. 36):

1. Contribuir a la unificación internacional de los ordenamientos jurídicos sobre conocimientos de embarque.

2. A establecer el plazo de un año para la prescripción de acciones por pérdidas y averías lo que se traduce en una solución rápida de los litigios.

3. Establecer la unificación de los derechos del poseedor del conocimiento de embarque frente al porteador.

4. Implementar un equilibrio de intereses frente a armadores y cargadores sobre las cláusulas que eximían la responsabilidad del por- teador aunque se estableció la responsabilidad subjetiva por culpa del porteador.

En su momento fue considerado como un éxito por el gran número de países que la suscribieron, casi 73 , incluyendo aquellos estimados como de mayor importancia en el transporte marítimo, pues se dice que las tres cuartas partes del transporte mundial a finales de 1960 se encontraban reguladas con contratos en los cuales eran aplicables las Reglas de La Haya.

La experiencia de casi treinta años en la aplicación de dicha convención hizo necesario revisar el texto para adecuarlo a la realidad del transporte marítimo iniciando un proceso de modificaciones que romperá con la uniformidad jurídica alcanzada hasta ese momento. Se apunta que las principales razones que se tomaron para llevar a cabo esta revisión fueron de carácter político, económico, técnico y jurídico (Espinoza, 1991, pp. 37-38).

Para 1959, el Comité Internacional Marítimo, aprobó en Rijeka un proyecto de revisión del Convenio de Bruselas. Pero se necesitaría conformar un comité de expertos, así como diversas sesiones entre los años de 1960 y 1963 en Londres, París y Estocolmo para lograr un texto uniforme modificatorio. Será el 23 de febrero de 1968, la fecha en que se aprobó el primer protocolo modificatorio de la convención conocido como Reglas de La Haya-Wisby, en honor de la ciudad de Wisby en Gotland.

Este protocolo modificatorio, que entró en vigor el 23 de junio de 1977, introduce cambios, 
principalmente en el ámbito de aplicación otorgando un carácter internacional; así como en la limitación cuantitativa de la responsabilidad del porteador o cálculo de la indemnización del porteador, la prórroga de prescripción, la utilización de "paletas" y contenedores. Pero entre los cambios más importantes en el ámbito de los documentos de transporte estuvo el valor probatorio del conocimiento de embarque en manos de terceros.

Respecto a su ámbito de aplicación se añaden dos criterios interesantes: 1) el lugar de carga en un Estado contratante; es decir, incorporar el lugar del puerto de descarga en un Estado contratante, y 2) el uso de las cláusulas Paramount con las cuales se pueden remitir a la convención de manera voluntaria. El segundo protocolo modificatorio llegará a consecuencia de la denominada "crisis del patrón oro" que consistió en el abandono del parámetro de este metal como método de conversión del Fondo Monetario Internacional con lo cual se tuvo la necesidad de llevar a cabo su modificación.

Este nuevo protocolo fue firmado el 21 de diciembre de 1979 en Bruselas entrando en vigor el 14 de febrero de 1984 y ratificado por Bélgica, Canadá, Dinamarca, Ecuador, Finlandia, Francia, Grecia, Italia, Japón, Luxemburgo, México, Noruega, Holanda, Polonia, España, Suecia, Suiza e Inglaterra.

Pues bien, estos protocolos tuvieron como objetivo modificar el límite de indemnización conforme a los derechos especiales de giro o "Special Drawing Rights" por bulto o unidad o a dos uni- dades de cuenta por kilogramo de peso bruto de las mercancías perdidas o dañadas, aplicándose el límite más elevado. Asimismo, se modernizaron la responsabilidad extracontractual del porteador y sus dependientes, mediante la adición del artículo 4 bis.

Durante los siguientes años en los cuales se aplicaron las denominadas Reglas de La HayaWisby, se confabuló por parte de los países predominantemente "cargadores", un bloque de oposición con la finalidad de que no se continuase con un régimen de "aligerar" la responsabilidad de los porteadores marítimos. Este bloque se encontraba conformado por el denominado "grupo 77", el cual presentó formalmente su protesta en Nueva Delhi, en 1968, ante la Conferencia de las Naciones Unidas sobre Comercio y Desarrollo (UNCTAD).

Este grupo conformado en la mayoría por países afroasiáticos y latinoamericanos, reclamaba que la Convención de Bruselas establecía un sistema poco equilibrado y por ende injusto entre los intereses de los transportadores y los cargadores, pues había sido elaborado finalmente por países industrializados, así como generar ambigüedades y altos costos en el transporte y sus seguros.

Por tanto, la pretensión de dicho grupo era precisamente dar a conocer las condiciones inequitativas entre porteadores y cargadores, por lo que era evidente crear un nuevo sistema jurídico internacional que fomentara equidad en las relaciones contractuales de porteadores y cargadores. Ante estas pretensiones, la con- 
ferencia solicitó a la Comisión de las Naciones Unidas para el Derecho Mercantil Internacional que conformase un grupo de trabajo con expertos internacionales en el derecho marítimo, el cual quedó conformado por delegados de veintiún países.

El grupo de trabajo elaboró un proyecto, resultado de ocho sesiones, totalmente distinto desde el punto de vista técnico-jurídico en razón de permitir en un convenio internacional formulaciones abstractas con contenido genérico y no únicamente una delimitación casuística predominante en el derecho anglosajón. Dicho proyectó quedó aprobado primeramente el 15 de diciembre de 1976 por la Asamblea General de las Naciones Unidas y, posteriormente, el 31 de marzo de 1978 fue aprobado por la conferencia diplomática celebrada en Hamburgo. El nuevo texto se denominó como Convenio de las Naciones Unidas sobre el Transporte de Mercancías por Mar, también conocido como "Reglas de Hamburgo".

Las Reglas de Hamburgo estaban compuestas por 34 artículos distribuidos en siete partes; entre los que se encuentran los artículos 14 a 18 denominados como "documentos de transporte". Asimismo, contempla dos anexos: conceso y la resolución de la conferencia. Fue publicado en castellano, francés, inglés, ruso, árabe y chino. Uno de los principales propósitos de este ordenamiento fue, sin duda, mejorar y sustituir las Reglas de La Haya así como la uniformidad internacional que buscaba "extender el alcance de estas reglas al mayor número de expediciones marítimas" pero excluyendo a los contratos de fletamento, postulado que se encuentra en el artículo 2. Es considerado de vanguardia la regulación del transporte sobre cubierta por parte de las Reglas de Hamburgo.

Este ordenamiento internacional otorgó una mayor flexibilidad en cuanto al reconocimiento de los documentos de transporte que son utilizados en la práctica marítima, los cuales no se encontraban reconocidos por los convenios anteriores. Esta flexibilidad queda manifiesta en el artículo 18 al permitir la validez de las cartas de porte marítimas no transmisibles y en el artículo 17 con las denominadas cartas de garantía. Precisamente estas cartas de garantías tienen un valor entre el cargador y el transportador al conferirle un derecho a este último para poder reclamar los daños y perjuicios a consecuencia de omitir una reserva en el conocimiento de embarque.

Es de reconocerse que la propia convención reconoce el uso de la tecnología al quedar plasmado en el artículo 1, inciso 8, la aceptación del telegrama o télex en la realización del contrato de transporte. Además de reconocerle validez a la firma consignada en facsímil, perforada, estampada, en símbolos o registrada por cualquier otro medio mecánico o electrónico con la salvedad que fuese compatible con las leyes del país donde se emite el conocimiento de embarque (Ravina, 1982, p. 31).

Por tanto, este convenio, a diferencia de las Reglas de La Haya-Wisby regula con mayor amplitud las menciones que deben incluirse en el conocimiento de embarque. Precisamente con 
respecto a los documentos de transporte se define que el conocimiento de embarque es el más importante, por ello se destacan seis puntos principales:

1. el conocimiento de embarque puede ser firmado por cualquier persona autorizada por el porteador sin importar si la firma es manuscrita, impresa en facsímil, perforada, estampada o registrada con cualquier medio mecánico o electrónico;

2. la omisión de los datos que constituyen el contenido del conocimiento no afecta su validez;

3. la posibilidad de realizar reservas siempre y cuando concurren "motivos razonables para sospechar" de la exactitud de los datos consignados en el conocimiento;

4. el valor probatorio iuris tantum para el porteador de haber tomado a su cargo las mercancías, tal y como aparecen descritas en el conocimiento;

5. establecer las garantías por el porteador sobre la exactitud de los datos de las mercancías y,

6. la permisibilidad de la emisión de documentos distintos al conocimiento de embarque y que el convenio no especifica. En general, la convención permite separar entre el conocimiento de embarque y el contrato de transporte constituyendo este último el objeto del convenio.
Ahora bien, es importante resaltar la apreciación de Emparanza Sobejano (1994 pp. 54-55) al señalar que "desde el punto de vista documental" no es indispensable la expedición del conocimiento de embarque para que se apliquen las Reglas de Hamburgo, contrario a lo que sucedía con las Reglas de La Haya-Wisby. Claro está, que además tienen la finalidad de ser un ordenamiento más homogéneo mediante la "prohibición" de establecer reservas sobre la aplicación del convenio.

Otro punto de vista, que se debe tener en cuenta con la pretendida unificación del contrato de transporte internacional de mercancías por mar, como ya vimos, es precisamente la propia pluralidad de convenios en esta materia. Lo anterior se traduce en incertidumbre e inseguridad jurídica para los operadores del tráfico marítimo.

\section{DESMATERIALIZACIÓN DEL CONOCIMIENTO DE EMBARQUE Y LA ELECTRONIFICACIÓN DEL CONTRATO DE TRANSPORTE}

El binomio documento y derecho trae como resultado un derecho incorporado en un soporte material, principalmente en papel. Pues bien, esa incorporación del derecho en el documento ha sido el mayor éxito de los títulos-valor en el tráfico jurídico derivado de su fácil transmisión, a lo que se conoce como función económicajurídica. Sin embargo, este mismo rasgo de "éxito" deja de serlo, cuando se comienzan a "masificar" indiscriminadamente la expedición de títulos-valor "acompañado a los costes de im- 
presión, cuidado y manipulación de los mismos, principalmente en aquellos pertenecientes al sistema financiero" (García y Lastres, 2006, pp. 776-778).

Esta "masificación" ha generado que en el momento de ejercitar el derecho incorporado surjan dos principales problemas: el primero, la necesidad de tener la posesión material del documento y, el segundo, que su transmisión se realice con las formalidades de ley; por ejemplo, endosos al dorso o al reverso del mismo documento. La solución se ha concentrado en sustituir la emisión física del documento que incorpora el derecho documentado mediante su registro o inscripción contable. De esta manera, queda plasmado todo su "historial de vida": quién es su titular, las veces que fue transmitido y a quién, si además se constituyeron derechos reales de garantía y en su caso si ya se extinguieron. Esto hace que se desincorpore el derecho documentado para visualizarse por medio de un asiento registral.

Por tanto, la nota característica de la "desmaterialización o desincorporación” de los títulos-valor, en este caso del conocimiento de embarque, será precisamente el separar el derecho documentado del soporte físico que es el papel; ya sea para que el derecho que se vaya a crear, se vaya a transmitir o se tenga que ejercitar "prescinda de la producción, entrega o presentación del papel que lo contiene" (Paz-Ares, 1996, p. 17, cursiva mía).

Esto ha sido "incitado" de alguna manera con el uso de las nuevas tecnologías, concretamente del internet y de nuevos instrumentos de almacenamiento portátiles al servicio de la información: memorias flash USB, DVD, etc. De ahí que se hable ahora de una "revolución de las telecomunicaciones y de la informática” (Gómez, 2011, p. 103).

Esta sustitución entre papel y nuevos soportes electrónicos tiende a convertir a la sociedad en una paperless society (Devescovi, 1991, p. 9, cursivas mías), pues además se debe tener en cuenta que en el uso de los correos electrónicos se llega también a incrementar el uso del papel por la impresión de esos mismos correos, por lo que no desaparece completamente el uso del papel; pues si bien lo único que ha facilitado el manejo de las nuevas tecnologías es la rapidez en la transmisión de la información contenida en los documentos, no se deja de prescindir totalmente del papel.

De esta manera los "valores documentados emitidos en masa" constituyen el origen principal de la crisis sobre la eficacia y utilidad de los documentos en papel y, principalmente, en el ámbito jurídico de aquellos con características cartulares. La aparente solución también se ha encontrado en la informática y en el uso de nuevas tecnologías de software y hardware al cambiar el papel por el uso de bytes. Así, la incorporación del derecho documentado en soporte papel viene a ser sustituido por caracteres binarios, que no siempre excluyen la utilización del papel. En el caso de los documentos de transporte, el problema no es la "masificación de documentos" durante el tráfico comercial, sino la "incidencia en el mundo de los transportes de las modernas 
técnicas de comunicación a distancia a través de registros informáticos y transmisión electrónica de datos" (Jiménez, 1998, p. 56).

Con lo cual, la informática y la ciencia jurídica llegan a interactuar en beneficio de la sociedad, principalmente en la actividad mercantil, sobre todo en la contratación electrónica (e-commerce) mediante el pacto de relaciones jurídicas-comerciales a través del principio de la autonomía de la voluntad (Illescas, 2009, p. 37). La posibilidad de llevar a cabo esas relaciones de carácter privado se logra por medio de ciertos postulados que rigen el derecho del comercio electrónico con el uso de las nuevas tecnologías. Estos principios son:

1. equivalencia funcional de los actos electrónicos respecto de los autógrafos o manuales,

2. neutralidad tecnológica en las disposiciones que regulan el comercio electrónico,

3. no alteración al derecho preexistente de obligaciones y contratos,

4. buena fe en los actos de comercio electrónico $\mathrm{y}$,

5. libertad de pacto y su ejercicio.

Pero cuando se refieren a cuestiones de orden público-económico, como lo es en el caso de los conocimientos de embarque, es necesario que exista una "previa regulación jurídica y su respectiva armonización tanto nacional como internacional, en el que se autorice el uso de las nuevas tecnologías" (Madrid, 1996, p. 2916).
Pues bien, es precisamente el uso de las nuevas tecnologías y la implementación por analogía de los principios que rigen el derecho del comercio electrónico, los que vendrán a darle un nuevo matiz a la teoría de la incorporación en los títulos-valor y, en consecuencia, de los conocimientos de embarque al ser posible la creación de títulos-valor electrónicos que contengan una anotación informática y ya no en un simple papel. Así, tenemos que la tendencia de cambio en el soporte papel entre la utilización de un soporte inmaterial o intangible representado en bytes da como consecuencia la implementación y regulación jurídica del documento electrónico.

El primer antecedente legislativo internacional sobre el uso de las nuevas tecnologías en los actos jurídicos, lo encontramos en 1996 con la Ley Modelo de la Comisión de Naciones Unidas para el Derecho Mercantil Internacional sobre Comercio Electrónico celebrado en Nueva York (en adelante Ley Modelo). Se estableció en los artículos 16 y 17 la denominada "electronificación del contrato de transporte". En el artículo 16 regula todos aquellos actos que se encuentren relacionados con el contrato de transporte de mercancías y, el artículo 17, exclusivamente los documentos de transporte. En general, establece la posibilidad de que la titularidad de las mercancías pueda transmitirse por medios electrónicos mediante la anotación en el registro, previo acuerdo de las partes contratantes.

Por otra parte, el primer antecedente legislativo de carácter internacional en el uso del conocimiento de embarque, concebido bajo un formato electrónico con las Reglas Uniformes sobre 
el Conocimiento de Embarque Electrónico, elaboradas por el Comité Marítimo Internacional mediante una conferencia celebrada en París en 1990. Estas disposiciones “regularon el procedimiento, la forma y contenido de la recepción de los mensajes, la notificación de la fecha y lugar de la mercancía, las condiciones generales del contrato de transporte, el derecho de control y de la sustitución del conocimiento en soporte electrónico" (Sánchez, 2010, p. 231).

Este ordenamiento, en voces de algunos expertos, ha sido considerado como "uno de los más trascendentales intentos que establecieron un procedimiento de emisión, recepción y de negociación de los conocimientos de embarque electrónico" (Martín, 2000, p. 30). Se encuentra compuesto de once reglas, en las que sobresale el ámbito de aplicación al basarse en el principio "whenever the parties so agree"; "siempre que las partes así lo acuerden”. Es decir, cuenta con una aplicación consensual en la emisión del conocimiento electrónico “abierto", pues su funcionamiento se basa en una serie de notificaciones entre el porteador y el cargador. A su vez, el adquiriente mediante una clave privada estará legitimado para retirar las mercancías transportadas. Sin embargo, esta normativa no es exclusiva de los transportes marítimos al ser también aplicable a cualquier otra clase de transporte.

Para la CNUDMI, desde su nacimiento, el GT-IV tuvo como objeto de estudio el conocimiento de embarque y el uso de intercambio electrónico de datos o EDI. Posteriormente en el año 2005, este mismo grupo llevó a cabo el estudio y adopción de un instrumento internacional re- lativo a la contratación electrónica denominado Convención de las Naciones Unidas sobre la Utilización de las Comunicaciones Electrónicas en los Contratos Internacionales, (en adelante ECC, por sus iniciales en inglés).

Este instrumento jurídico hizo realidad la reglamentación en el ámbito internacional, con carácter vinculante a los países que eran parte de ella, el uso de agentes inteligentes o sistemas automatizados de mensajes en la contratación electrónica, los cuales eran capaces de buscar agentes similares, negociar y contratar entre sí de modo automatizado a partir de la escala de prioridades y criterios de negociación previamente programados. Sin embargo, es importante resaltar que de conformidad con su artículo primero este ordenamiento excluye en su aplicación, al conocimiento de embarque o de cualquier otro título transferible que faculte a sus porteadores o beneficiarios para reclamar la entrega de mercancías. La aportación de esta normativa fue precisamente la regulación de los procedimientos técnicos que posteriormente serán adoptados por las Reglas de Rotterdam. Para ello es interesante la apreciación de Recalde Castells (2010) al comparar y hacer notar la coincidencia en la redacción de la definición del artículo 1.18 sobre el documento electrónico de transporte en las RR con el artículo que define la comunicación electrónica y el documento electrónico del ECC (p. 174).

Por tanto, la tendencia internacional sobre la regulación del contrato de transporte ha tenido como protagonista principal la emisión del conocimiento de embarque electrónico. Por ejemplo, 
en España, el artículo 250 del proyecto de la Ley General de Navegación Marítima prevé la utilización del conocimiento de embarque electrónico. En el caso del contrato de transporte terrestre de mercancías, la Ley 15 de 2009, del 11 de noviembre, contempla el uso de la carta de porte electrónica.

En el caso de Colombia, debemos traer a colación el artículo 12 de la Ley 527 de 1999, el cual establece los requisitos que deberán cumplir toda información electrónica en el ámbito del comercio internacional.

Además de España y Colombia, la República de Corea, es otro país que en su legislación viene reglamentando el conocimiento de embarque electrónico por medio del artículo 862 del Código de Comercio de Corea del 3 de agosto de 2007. Asimismo, el decreto presidencial del 4 de agosto de 2008, que forma el complemento de tal articulado. Por medio de esta normativa se le reconoce validez legal al conocimiento de embarque electrónico, en lo cual la persona física o moral deberá estar inscrita en un "registro de títulos electrónicos" facilitando sus datos personales para poder obtener acceso a los servicios del registro. Además, las partes deberán contar con una firma electrónica que será autenticada por un proveedor de servicios de certificación coreano. ${ }^{1}$ Lo anterior constituye el antecedente en el derecho comparado sobre el uso de los

1 Para mayor información sobre el funcionamiento del conocimiento de embarque electrónico regulado en la legislación coreana puede consultarse los párrafos 30 al 32 del Documento A/CN.9/62 Asamblea General. Labor actual y posible labor futura en materia de comercio electrónico. $43^{\circ}$ periodo de sesiones en Nueva York, 29 de junio a 9 de julio de 2010. Recuperado de http://daccess-dds-ny.un.org/doc/ UNDOC/GEN/V10/527/77/PDF/V1052777.pdf?OpenElement documentos de transporte electrónico. Para las RR, el inciso a) del artículo 8 dispone que el documento de transporte puede ser consignado en un soporte electrónico, siempre y cuando la emisión y el subsiguiente empleo de este se haga con el consentimiento del porteador y del cargador. Por tanto, el uso del documento de transporte en soporte electrónico no podrá quedar al arbitrio de una de las partes, si no es necesario el consenso de ambas partes; pues se encuentra sujeto al margen de la autonomía de la voluntad. Esta autonomía también se ve reflejada en el artículo 35 al otorgarle al cargador la posibilidad de elegir si dicho documento será emitido con carácter negociable o no negociable, y en su caso en soporte electrónico.

Por tanto, el porteador y el cargador se pondrán de acuerdo sobre el método de emisión y transmisión, la integridad del mensaje de datos, la manera en que el tenedor estará legitimado para la entrega de la mercancía o la forma en que se acredite fehacientemente que se le entregó al tenedor y los modos en que el documento ha dejado de tener validez. Lo único que queda al arbitrio del porteador es la emisión y el contenido que deberá contener el documento de conformidad en el artículo 1.14 de las RR.

De esta manera podemos asegurar que el inconveniente de la emisión del documento de transporte en soporte electrónico queda finalmente a decisión exclusiva del porteador contrariando en cierta medida la ratio legis de las reglas, puesto que en el acuerdo de su aprobación se hizo hincapié en la utilización de los procedimientos electrónicos. Nuevamente a los porteadores se 
les favorece en la toma de decisiones, al tener la "última palabra" en el uso de los documentos de transporte electrónicos debido a que si no desean invertir económicamente en la tecnología necesaria para llevarla a cabo, seguramente esta pretensión se convertirá en "letra muerta".

En definitiva, el principal objetivo en el proceso de "desincorporación" del título-valor en el entorno electrónico, es precisamente la traslación de la posesión a ese entorno al tratar de prescindir en el uso del papel como soporte mediante la búsqueda de métodos fiables para la transmisión electrónica del derecho incorporado en los documentos negociables, pero en especial en ámbito de los documentos de transporte marítimo. Para ello, la CNUDMI a través del GT-IV ha elaborado algunos postulados que regulan y sobre todo logran la pretendida "equivalencia funcional" entre los títulos-valores en soporte papel y electrónico. Por ello a través de los grupos de trabajo III y IV sobre comercio electrónico y transporte respectivamente desde el año 2000 en su $33^{\circ}$ periodo de sesiones celebrado en Nueva York, han recopilado diversas opiniones relativas a los principales temas del comercio electrónico. Los tres temas más importantes que se abordaron fueron: a) la contratación electrónica incorporada en la compraventa internacional de mercancías, b) la solución de controversias a través de medios electrónicos y, c) la desmaterialización de los documentos de carácter patrimonial, principalmente de aquellos utilizados en el contrato de transporte marítimo de mercancías. ${ }^{2}$ De esta manera, la CNUDMI ha

Documento A/55/17 Asamblea General. $55^{\circ}$ periodo de sesiones, suplemento número 17 . Informe de la CNUDMI sobre su $33^{\circ}$ desarrollado una serie de trabajos con miras al estudio de los documentos electrónicos y sobre todo a la transferencia de derechos en el ámbito del transporte marítimo internacional, estudios de los cuales nos referiremos más adelante.

\section{CONVENIO DE LAS NACIONES UNIDAS SOBRE EL CONTRATO DE TRANSPORTE INTERNACIONAL DE MERCANCÍAS TOTAL O PARCIALMENTE MARÍTIMO. REGLAS DE ROTTERDAM DE 2008}

A partir de los conflictos existentes entre los países considerados proporteadores y pronavieros, la CNUDMI convocó a un grupo de trabajo sobre el derecho del transporte presidido por el profesor español Rafael Illescas. La finalidad era elaborar un texto jurídico de carácter internacional que regulara el transporte de mercaderías. Después de siete años preparatorios, el 11 de diciembre de 2008 nació el Convenio de las Naciones Unidas sobre el Contrato de Transporte Internacional de Mercaderías Total o Parcialmente Marítimo también denominado "Reglas de Rotterdam" (RR); acogiendo el nombre de la ciudad en la que se llevó a cabo el acto protocolario de firma el día 23 de septiembre de 2009, y que en opinión de Aguirre (2013):

En realidad pudieron denominarlas, con mejor fundamento, Reglas de New York 2008, ya que su artículo final reza: "Hecho en Nueva York el undécimo día de diciembre de dos mil ocho en

periodo de sesiones 12 de junio a 7 de julio de 2000. Recuperado en http://daccess-dds-ny.un.org/doc/UNDOC/GEN/N00/644/29/IMG/ N0064429.pdf?OpenElement 
un solo original cuyos textos en árabe, chino, español, francés, inglés y ruso son igualmente auténticos". Parecería que alguien pensó que convenía darles un nombre con sabor a mar y tradición de puerto. Ya teníamos Reglas de La Haya y luego Reglas de Hamburgo, así que llevaron el proyecto hasta Rotterdam y allí lo firmaron de nuevo... (p. 234).

En la fecha en que se escribía este artículo, 25 países lo habían firmado y únicamente tres de ellos lo habían ratificado, requiriéndose el depósito de veinte instrumentos para que el convenio entrara en vigor. ${ }^{3}$ Este texto cuenta con el apoyo de la Unión Europea, tal y como se desprende del artículo 11 de la Resolución del Parlamento Europeo sobre metas estratégicas y recomendaciones para la política europea del transporte marítimo hasta el 2018, de fecha 23 de marzo de 2010, documento que no tiene el carácter de vinculante. También ha sido bien acogido por "diversas asociaciones marítimas europeas que representan el 90\% de la industria naval a nivel mundial" (Espinosa, 2013, p. 355, cursivas mías) entre las que se encuentran la European Community Shipowners Association (ECSA), la International Chamber of Shipping (ICS), Baltic and International Maritime Council (BIMCO) y la World Shipping Council (WSC).

A diferencia de los anteriores ordenamientos internacionales, las RR tienen un ámbito de apli-

3 Los países que han firmado dicho texto han sido Armenia, Camerún, Congo, Dinamarca, España, Estados Unidos, Francia, Gabón, Ghana, Grecia, Guinea, Guinea-Bissau, Luxemburgo, Madagascar, Mali, Níger, Nigeria, Noruega, Países Bajos, Polonia, República Democrática del Congo, Senegal, Suecia, Suiza y Togo. Quienes lo han ratificado son Congo, España y Togo. Recuperado de uncitral.org/ uncitral/es/uncitral_texts/transport_goods/rotterdam_status.html. Se accedió $1^{\circ}$ de junio de 2014 cación más extenso con el propósito de conseguir un equilibrio entre las partes que lo suscriben. Sin embargo, también se ha criticado que se establecen nuevas restricciones a la libertad de los contratantes que no benefician al cargador ni al porteador, "pasando del principio de la autonomía contractual a un régimen imperativo", (Muñoz, 2012, p. 16) como por ejemplo, el derecho de control. Asimismo, se ha criticado la eliminación de la cláusula Paramount, vulnerando nuevamente el principio de autonomía contractual al dejar de considerar el lugar de expedición del documento de transporte al momento de establecer el ámbito de aplicación de este ordenamiento.

Pero también ha sido criticado por ser un documento extenso al quedar conformado por 18 capítulos con 96 artículos y cada uno de ellos con sus respectivos subnumerales, lo que hace complicado entender las 220 referencias que se mencionan en el texto, dificultando su interpretación, llegándose a afirmar que su redacción "carece de técnica jurídica además de que su técnica legislativa tiene un carácter anglosajón" (Arroyo, 2013, p. 178).

Estas críticas de forma y sobre todo de fondo han sido abanderadas por diversos grupos de especialistas en la materia. Las primeras críticas vinieron de la mano en 2009 con la publicación del documento intitulado "Algunas preocupaciones concretas sobre las Reglas de Rotterdam", redactado por los profesores Svante 0. Johansson, Barry Oland, Kay Pysden, Jan Ramberg, Douglas G. Schmitt y William Tetley C.M., Q.C. Escrito que también fue conocido como “El 
documento de los seis", y después con la inclusión de los profesores José María Alcántara, Frazer Hunt y Julio Vidal como "El documento de los nueve". Posteriormente, estas críticas fueron plasmadas en la Declaración de Montevideo contra las Reglas de Rotterdam, el 20 de octubre de 2010 (Aguirre, 2013, pp. 235-237). Entre otros muchos aportes, a favor y en contra, merece destacarse el trabajo doctor José Vicente Guzmán, de Colombia a favor de las Reglas de Rotterdam denominado "Una respuesta latinoamericana a la Declaración de Montevideo". Ahora bien, una de las grandes novedades de este ordenamiento es la sustitución de la figura "conocimiento de embarque" por la denominación "documentos de transporte" y, principalmente, su regulación mediante soporte electrónico a los que nombra "documentos electrónicos del transporte", expresiones que también fueron criticadas en la Declaración de Montevideo contra las Reglas de Rotterdam. ${ }^{4}$

El documento electrónico de transporte es contemplado en el artículo 1.18 al definirse como

la información consignada en uno o más mensajes emitidos por el porteador mediante comunicación electrónica, en virtud de un contrato de transporte, incluida la información lógicamente asociada al documento electróni-

4 El punto siete dice: "Elimina el término conocimiento de embarque, consagrado en todas las legislaciones, doctrina y jurisprudencia, sustituyéndolo por vagos términos de documento de transporte o documento de transporte electrónico". Declaración que ha sido respaldada por 72 abogados especialistas marítimos, así como empresarios principalmente de países de América Latina como Argentina, Brasil, Chile, Colombia, Ecuador, México, Nicaragua, Paraguay, Perú, Uruguay; así como de Canadá y España. Documento disponible íntegramente en la Revista Anuario de Derecho Marítimo XXVIII, Instituto Madrileño de Desarrollo Comunidad de Madrid, Consejería de Economía y Hacienda (2011, pp. 687-691). co de transporte en forma de datos adjuntos o vinculada de alguna otra forma al mismo porteador, simultáneamente a su emisión o después de ésta, de tal modo haya pasado a formar parte de todo el documento electrónico de transporte... (Convenio de las Naciones Unidas sobre el Contrato de Compraventa Internacional de Mercancías Total o Parcialmente Marítimo, 2008)

Y finalizando al hacer referencia a su principal objetivo, probar que: 1) "el porteador o una parte ejecutante ha recibido las mercancías con arreglo a un contrato de transporte" y, 2) "contenga un contrato de transporte".

Por su parte, el artículo 8 regula el empleo y la eficacia de los documentos electrónicos de transporte, disponiendo que, a reserva de los requisitos enunciados en las reglas:

a) todo lo que deba figurar en un documento de transporte con arreglo al instrumento internacional, puede ser consignado en un documento electrónico de transporte, siempre y cuando la emisión y el subsiguiente empleo del mismo se haga con el consentimiento del porteador y del cargador; y, b) la emisión, el control exclusivo o la transferencia del documento electrónico de transporte surtirá el mismo efecto que la emisión, la posesión o la transferencia de un documento de transporte.

Por tanto, al hacer entrega el cargador de las mercancías para su transporte al porteador o a una parte ejecutante, el cargador o el cargador documentario con el consentimiento del porteador, tiene derecho a obtener: a) un documento de transporte en soporte papel o electrónico no 
negociable; o b) un documento de transporte en soporte papel o electrónico negociable, salvo que el cargador y el porteador hayan convenido no utilizar ni el uno ni el otro, o que al llegar a utilizar tales documentos sea contrario a la costumbre o los usos del comercio o a la práctica del tráfico mercantil (artículo 35).

De esta manera se consagra en las RR, el principio de la equivalencia funcional del documento electrónico (soporte inmaterial) con el documento en soporte de papel, como idea orientadora de toda la normativa referente al comercio electrónico. Así tenemos que, la emisión de un documento de transporte o de un documento electrónico de transporte tendrá lugar salvo que el cargador y el porteador hayan convenido utilizarlos, o que la expedición de alguno de estos documentos sea contraria a la costumbre, a la práctica o los usos del comercio.

En definitiva, este nuevo ordenamiento internacional desde el punto de vista de la documentación representa un gran esfuerzo para sustituir el papel por el formato electrónico. Al igual que lo fueron sus antecesores, constituye una ambiciosa solución para armonizar y uniformar el contrato de transporte marítimo internacional al resolver las diferencias entre porteadores y cargadores otorgando seguridad y certeza jurídica en la relación contractual. Una normativa que si bien se adecua a los tiempos tecnológicos que se están viviendo pero que al regular a los documentos de transporte, en nuestra opinión su naturaleza jurídica es distinta al dejar de ser un título-valor. Es un título representativo de mercancías que llega a transmutarse a un título sui generis al poseer ahora la naturaleza jurídica de un documento de legitimación.

\section{EQUIVALENCIA FUNCIONAL EN EL EMPLEO DE DOCUMENTOS DE TRANSPORTE ELECTRÓNICOS}

El conocimiento de embarque como un simple recibo que además contiene las cláusulas del contrato de transporte y como título representativo de mercancías (767 del Código de Comercio de Colombia), cuenta con tres principales funciones:

a. Función probatoria de la carga constituyéndose como título probatorio del transporte marítimo (artículos 653 y 709, Código de Comercio español, 1639 del Código colombiano);

b. Función acreditativa de la existencia de un crédito de restitución de las mercancías a través de la representación de un título de crédito contra el capitán (artículos 715 y 716, Código de Comercio español, 1640 del Código colombiano) y,

c. Función representativa de las mercancías mediante la representación de un título de tradición de las mercancías (artículo 708, segundo párrafo, del Código de Comercio español y 644 del Código de Comercio colombiano).

Esta triple función reúne el conocimiento de embarque mediante su regulación, tanto de normativas de países pertenecientes a sistemas jurídicos latinos y sajones. La primeras dos funciones 
que caracterizan a este tipo de documento, son de naturaleza muy esencial, pues el documento como tal, funge como un medio de prueba física de la existencia de las condiciones pactadas en el contrato de transporte marítimo. Esta función probatoria sobre las condiciones físicas de las mercancías a partir de su descripción surge una presunción iuris tantum con lo cual es aplicable a las relaciones entre el porteador y el cargador pero en el caso de terceros adquirientes de buena fe del conocimiento se concibe una presunción iuris et de iure (Pendón, 1994, p. 129). Ahora bien, la función probatoria de la recepción de las mercancías se traduce en lo que se conoce técnicamente como la situación receptiva (certificativa) y de legitimación de la persona a quien se le entregarán las mercancías.

Como ha quedado anotado, el conocimiento de embarque funge con una función probatoria y contractual, en donde cada una tendrá diversas características atendiendo a su propia naturaleza. Así, la función probatoria se centra en la recepción, entrega y custodia de las mercancías, la contractual tendrá la naturaleza jurídica-negocial de la obligación de realizar el transporte.

Pero la función probatoria del conocimiento de embarque llega a desaparecer cuando se declara en el propio documento que se "ignora peso y contenido" de las mercancías. Lo anterior trae como consecuencia que el destinatario o receptor de las mercancías deba probar por otros medios de prueba distintos al documento, la existencia efectiva del daño exigiendo la responsabilidad del porteador por su incumplimiento a la obligación de entregar las mercancías en el mismo estado en que se encontraban al momento de habérsele entregado; es decir, mismo peso y cantidad.

Y, por último, una tercera función que tiene el conocimiento de embarque es la denominada función representativa también conocida eficacia traslativa (Asarelli, 2008, p. 243), la cual contribuye al progreso del comercio marítimo con la simplificación en la venta sobre documentos, tal y como sucede en la venta Cif. En esta función se destaca como un documento traslativo de dominio y de los derechos reales que se conciben sobre las mercancías que el propio documento representa.

Para Recalde Castells (1999, pp. 47-49), la función representativa viene a ser el "paralelismo" que se produce entre el conocimiento de embarque como "símbolo" de las mercancías embarcadas; es decir una "traditio simbólica de las mercancías". Pero además cabe preguntarse si la función representativa o eficacia traslativa del conocimiento de embarque abarca exclusivamente la mera representación simbólica de las mercancías como un derecho de crédito a su entrega o además constituye la representación de un derecho real sobre ellas. Estas dos perspectivas han constituido en la doctrina, la "eficacia representativa" del conocimiento de embarque al "facilitar la transmisión de derechos reales sobre las mercancías puestas en viaje", pues precisamente se concibe que llegan a incorporar un derecho real. Tal apreciación imputa al tenedor del conocimiento de embarque que ha adquirido la propiedad de las mercancías. Sin embargo, el considerar que el conoci- 
miento de embarque encuentra su naturaleza en el contenido del derecho incorporado, debe de rechazarse, ya que dependiendo de los actos jurídicos que se celebren será el contenido del supuesto derecho real ahí documentado: compraventa, cesión de crédito, etc.

Por último, existe otro elemento que constituye la eficacia traslativa del conocimiento de embarque y es la recepción de las mercancías por el porteador; pues mientas no se lleve a cabo la entrega de estas no nacerá ninguna relación jurídica entre el deudor-emisor del título y el porteador y el acreedor cartular no podrá obtener su restitución. Tan es así, que la transmisión del conocimiento de embarque es considerada como una relación "restitutoria" donde el tenedor de dicho documento se considera también el poseedor de los bienes objeto de crédito; siempre y cuando concurran los presupuestos de una posesión mediata como la validez del crédito sobre la entrega de las mercancías y que se hallen en poder del mediador o poseedor inmediato, así como la voluntad del mediador de poseer para el acreedor.

Sin embargo, la "equivalencia funcional”, término no muy difícil de deducir, advierte precisamente una igualdad en dos vertientes. La primera, en la "estimación o valor" que se da entre el soporte inmaterial electrónico representando por bytes y el soporte material o físico, como lo es el papel, en donde en ambos casos supondrán un elemento que constituirá un documento. El segundo, con mayor importancia, una igualdad en la función como soporte ya sea inmaterial o material para documentar un derecho, que conforma un documento. Dicha función será el contener la información, en este caso el acto o hecho jurídico de que se trate.

De esta manera, la instrumentación electrónica del acto jurídico no podrá repercutir en su contenido, efectos, alcance y finalidad. De ahí que la doctrina también lo ha denominado como "principio de no discriminación" (Illescas, 2009, pp. 41-42). Su regulación y primera aparición la encontramos en el contenido del artículo 5 de la Ley Modelo, ya comentada, que señala: "No se negarán efectos jurídicos, validez o fuerza obligatoria a la información por la sola razón de que esté en forma de mensaje de datos". Aunque si bien es cierto, este principio es aplicable a la contratación electrónica, en otros ordenamientos ha quedo excluido tratándose de los títulos-valores, ya que el artículo 2.2 de la ECC, establece una excepción en la aplicación de los principios que contempla la referida ley modelo, en especial al principio de "equivalencia funcional".

El principio de "equivalencia funcional" aunque es aplicable al comercio electrónico, no se aplica de igual forma a los títulos-valores, ya que si bien dicho postulado permite la equiparación del soporte electrónico con el papel y la firma, se queda corto tratándose de las características propias de los títulos-valores: literalidad, abstracción, autonomía y circulación; pues no garantiza las reglas de transmisión del derecho incorporado bajo soporte electrónico y que fehacientemente se trate de un ejemplar único original como se explicará más adelante. 
Pero, la "equivalencia funcional" es un postulado que es considerado como la máxima en el derecho de la contratación electrónica y que ha sido adoptado por diversas legislaciones a nivel mundial. Concretamente en España, se ha adaptado mediante su inclusión implícitamente en el artículo 23.1, párrafos 1 y 3 de la Ley 34 de 2002, del 11 de julio de 2002, de Servicios de la Sociedad de la Información. En el caso de la legislación mexicana ha sido reconocido mediante decreto publicado en el Diario Oficial de la Federación de fecha 29 de mayo de 2000, que adiciona diversas disposiciones del Código de Comercio, principalmente el Título II denominado "Del comercio electrónico" que abarca los artículos 89 al 94. Por tanto, el principio de "equivalencia funcional" es el pilar fundamental para el reconocimiento de validez de los actos jurídicos que se lleven a cabo a través del uso de las nuevas tecnologías.

En otras palabras, la "equivalencia funcional" confiere que el negocio jurídico consignado en un soporte inmaterial tendrá los mismos efectos jurídicos que si fuese plasmado en papel. Claro que su excepción sobre la validez o invalidez del negocio jurídico también se estudiará en torno a la declaración viciada del consentimiento de las partes. Aunque también se contempla la excepción de aquellos documentos electrónicos de carácter público que presenten un defecto en su expedición podrán concedérseles un valor probatorio como documento privado. Es importante señalar que el "principio de equivalencia funcional" es también aplicable al uso de las firmas electrónicas y reconocida por la legislación y la jurisprudencia (Illescas, 2009, pp. 48-49).
Así tenemos que, si un documento es considerado auténtico porque ha sido creado o enviado por la persona que dice haberlo hecho en el momento en que ahí lo señala, cabe preguntarse ¿ cuándo se deberá considerar auténtico un documento en soporte electrónico? Si bien es difícil de validar la autoría del documento, no es imposible. Para ello se crearon la firma y el certificado electrónico. Aunque se ha dicho que la firma electrónica "no garantiza de manera total la identidad de la persona que ha suscrito el documento", aunado a ello el problema de la caducidad o vigencia de la firma y, principalmente de la certificación. Al respecto Gómez Díaz (2009) ha señalado que:

En este sentido, archivísticamente se plantea el problema de cómo verificar que un documento es auténtico una vez que ha expirado el plazo de vigencia de la firma o el certificado digital. Para evitar este problema hay mecanismos como el sellado digital, donde se certifica que en un determinado momento ese documento existía y era válido, si aseguramos que el documento no ha sido alterado, el documento sigue siendo válido. (p. 187)

Desde la perspectiva del derecho europeo, la equivalencia funcional ha tenido una corriente de implementación. Por ello, el artículo 9.1 de la Directiva 2000/31 de la Comunidad Europea, de 8 de junio de 2000, relativa a determinados aspectos jurídicos de los servicios de la sociedad de la información, en particular del comercio electrónico en el mercado interior, establece: el mandato que formula destinado a los Estados miembros de la UE para que sus ordena- 
mientos apliquen el principio de equivalencia funcional y garanticen la electronificación no sólo de contratos sino también de lo que el propio precepto califica como 'proceso contractual'... (Illescas, 2009, p. 288, cursivas mías)

Ahora bien, es mediante el principio de equivalencia funcional que las RR establecen que aquellos avisos redactados por escrito tendrán el mismo valor de aquellos que sean emitidos por comunicaciones electrónicas. Además, este principio es aplicado a la administración de los documentos de soporte en papel; es decir, en su conservación para ulteriores consultas y su no alteración con un "método fiable". Por ello, en el artículo 8, inciso b), de las RR se señala que "la emisión, el control exclusivo o la transferencia del documento electrónico de transporte surtirá el mismo efecto que la emisión, la posesión o la transferencia de un documento de transporte". Precisamente, la equivalencia entre papel y el formato electrónico estriba en las funciones que cumplen cada uno siendo importante establecer el valor probatorio de un mensaje de datos electrónico; la determinación del lugar en la formación del contrato, cláusulas y condiciones generales así como la atribución de la responsabilidad en caso de que se genere un mensaje de datos por error. Nuevamente debemos retomar la Ley Modelo, en especial los artículos 5 y 6 . Estos artículos de manera general señalan que cualquier acto que se lleve por escrito en papel, relacionado con el contrato de transporte quedará "satisfecho" si se lleva a cabo mediante un mensaje de datos electrónico. Lo anterior ha sido así en razón dar mayores facilidades y confianza en la práctica del comercio electrónico respetando ante todo el principio de autonomía de la voluntad.

Como ya quedó asentado, la utilización del formato electrónico en la emisión del documento de transporte es estrictamente consensual, con lo cual si las partes pactaron utilizar en sus actos jurídicos así como en todas aquellas comunicaciones que tuviesen en la relación contractual el formato tradicional de papel, es obvio que ante este supuesto no se aplicaría el principio de equivalencia funcional. Es de mencionar que, además del principio de equivalencia funcional, se encuentra otro postulado denominado "garantía de singularidad". Esta garantía consiste en que toda transmisión de obligaciones y derechos en los medios electrónicos se debe utilizar un sistema confiable para garantizar la particularidad de cada mensaje de datos evitando la transmisión de lo mismo a distintas personas. Su fundamento se encuentra en el tercer párrafo del artículo 17 de la mencionada Ley Modelo.

Con lo cual, la "singularidad" estriba en que una vez que el emisor ha transmitido por medios electrónicos aquel derecho u obligación, no puede volver a transmitirlo pues ya traspasó la titularidad de ese derecho u obligación. Es decir, la "negación de múltiples transmisiones del mismo derecho incompatibles entre sí; pero no se pretende negar la posible continuidad de un derecho" (Madrid, 1998, p. 113, cursivas mías). Por tal motivo, la implementación de las nuevas tecnologías en los documentos de transporte tienen como función primordial: 1) comprobar la existencia de obligaciones que se originan a partir de la celebración de los contratos de 
transporte y la recepción de las mercancías, 2) facilitar la transmisión de los documentos de transporte y, 3) un carácter representativo de las cosas transportadas. Aunque como lo refiere Jiménez (1998) “la atribución del valor probatorio a los datos e informaciones recogidos y transmitidos mediante procedimientos informáticos plantea el problema de garantizar la autenticidad del contenido de los registros o memorias electrónicas de los ordenadores" (p. 58).

Ahora bien, el principio de equivalencia funcional tiene su excepción, el cual será la "reversión al papel". Pues se puede llegar a dar el caso de que las partes contratantes en la relación jurídica derivada del contrato de transporte, hayan pactado el uso del documento de transporte electrónico así como de cualquier otro documento en ese mismo formato. Sin embargo, una determinada autoridad aduanera o portuaria puede exigir, según la normativa nacional, la constancia de dichas operaciones comerciales en formato papel, con lo cual coexistiría el documento en formato electrónico como en papel.

Ante este panorama, el multicitado artículo 17.5 de la Ley Modelo admite la posibilidad de que el acto jurídico o su transmisión en formato electrónico pueda mudar a un formato de papel o viceversa, pero no así la existencia simultánea en la circulación de ambos formatos en la representación de un mismo derecho o de su transmisión. Lo que crearía un "conflicto de interés en el momento de que los titulares de dichos documentos pretendieran ejercitarlos aunque probablemente predomine aquel emitido en soporte electrónico" (Madrid, 1998, p. 115).
Por otra parte, el "control sobre el documento electrónico", ha sido un concepto para matizar el fenómeno de la posesión y el efecto traslativo con connotaciones de contenido físico en el que se establece la asignación de derechos en papel, mediante términos como holder, tenedor o entrega. Lo que se busca es la fiabilidad en el proceso de transmisión de derechos a través de la integridad y veracidad de las declaraciones vertidas en la información plasmada de manera electrónica.

Para ello se debe tener en cuenta que precisamente aquellas transacciones que se realizan por medio de comunicaciones electrónicas se llevan a cabo con personas distantes; es decir "entre no presentes" y es intercambiada, aunque sigue siendo una información escrita. Es decir, se crea una "apariencia jurídica electrónica"; ya que esa información escrita sigue la secuencia procedimental vigente en el papel. De ahí, que la mayoría de las legislaciones que regulan la "desincorporación" en el papel, utilizan los términos con connotaciones de un soporte físico, tales como "posesión”, "porteador", "entrega", etc. (Alba, 2007, pp. 522-523).

Por tanto, en las transacciones electrónicas comerciales lo que fluye es la información escrita. De ahí, que de llegar a existir la "posesión electrónica", no tendría utilidad para la legitimación documental. Ahora bien, como ya se dijo, el control sobre el documento electrónico se llega a reflejar mediante la información escrita que haya sido plasmada en la pantalla del ordenador, pero no así la comprobación visual con la exhibición o presentación de la persona que lo posee. 
A raíz de lo anterior se han creado los "registros públicos" para la asignación de titularidades y la legitimación, en el almacenamiento y publicidad de la información escrita bajo la apariencia jurídica de la eficacia legitimadora. Son registros electrónicos centralizados en un entorno cerrado ya que debe ser contratado por las partes que desean tener acceso al él. Así, la apariencia jurídica electrónica debe tener como objetivo la conservación del régimen por la transmisión de derechos de crédito, así como la constitución y transmisión de derechos reales sobre las mercancías. En concreto se debe lograr una "apariencia de titularidad sobre el derecho a obtener la entrega de las mercancías". A su vez, el artículo 38 de las RR establece que todo documento de transporte de carácter electrónico deberá ser firmado a través del porteador o su representante legal por medio de la firma electrónica, la cual lo identificará con el documento haciendo mención de que el porteador lo autoriza.

Por otra parte, tal y como lo habíamos comentado en líneas anteriores, el principio de "equivalencia funcional" se considera insuficiente en los títulos-valores, pues es considerado una excepción en razón a la propia naturaleza de aquellos. Es decir, en los títulos-valores se requiere la necesidad de un ejemplar único y que dicho ejemplar sea presentado como documento original para el ejercicio del derecho en él incorporado. Situación que debe ser resuelta desde el punto de vista técnico ante la facilidad de copiar un archivo electrónico lo que trae como consecuencia la dificultad en diferenciar entre un archivo original y la copia.
Ahora bien, dicha excepción no ha sido un impedimento para que los Estados por medio de su legislación doméstica puedan regular el tratamiento electrónico de los títulos-valores como lo es con el pagaré electrónico. Es el caso de Estados Unidos es mediante la promulgación de las reglas de la Uniform Electronic Transaction Act (UETA) y la Electronic Signature in Global and National Commerce (E-SIGN) que se crea una legislación específica sobre la emisión y transferencia de los títulos cambiarios electrónicos mediante la aplicación del principio de "equivalencia funcional" encaminada a la posesión y los derechos de los tenedores del título-valor electrónico (Rico, 2014).

Por otra parte, para los negocios jurídicos creados y ejecutados vía electrónica no se debe producir un cambio en la sistematización de los negocios jurídicos en general, a lo que se le denomina como principio de "inalteración del preexistente derecho de obligaciones y contratos". Este principio lo podemos considerar en un segundo lugar dentro de un jerarquía de importancia después de la equivalencia funcional. Pero gracias a los principios sobre la inalteración de las reglas preexistentes en el derecho de las obligaciones, nacen otros como el principio de "libertad contractual en material de contratación electrónica". Este es un principio que se encuentra implícitamente dentro del postulado sobre "inalteración del preexistente derecho de obligaciones y contratos", pues como lo ha señalado Illescas (2009) “El soporte electrónico, en consecuencia, no excluye la libertad de pacto en un mayor grado o medida en que se excluye en la contratación verbal o manual" (p. 61, cursivas mías). 
Ahora bien, como consecuencia inmediata del "principio de inalteración" encontramos el principio de la "buena fe comercial". Si bien es reconocido en la mayoría de las legislaciones nacionales que regulan el comercio, ${ }^{5}$ este debe establecerse con mayor exigencia en las relaciones contractuales celebradas entre sujetos no presentes, como se hace en la contratación electrónica.

Pero independientemente de la inalteración de las reglas en las obligaciones y contratos, así como la buena fe contractual, la legislación debe tomar en cuenta los avances tecnológicos. Lo que hoy es novedad en unos pocos meses será obsoleto y tal vez sin tener manera de visualizar el contenido o información que se encuentra en el soporte electrónico. Para ello se debe prever mediante una norma que no limite el uso de determinada tecnología de reproducción, almacenaje o visualización. A esto se le conoce como principio de "neutralidad tecnológica." Además de los anteriores principios, es trascendental tener en cuenta otros que han sido impulsados por los trabajos preparatorios del GT-IV de la CNUDMI que promueven los fundamentos sobre la "equivalencia funcional" encaminada a la posesión y el derecho del tenedor del título-valor electrónico; así como los supuestos de "unicidad o singularidad" y "transferencia del control" como equivalente de la posesión, los cuales se abordaran más adelante.

5 En la legislación española este principio de buena fe se encuentra reconocido en el artículo 57 del Código de Comercio. En el caso de México se encuentra reglamentado en el artículo 6 bis del Código de Comercio como deber del comerciante de actuar conforme a los "usos honestos en materia industrial o comercial".

\section{PROCEDIMIENTO DE TRANSFERENCIA DE LOS DOCUMENTOS DE TRANSPORTE ELECTRÓNICOS}

Como ya se ha comentado, en el ámbito internacional, la propia CNUDMI ha encomendado al GT-IV, la elaboración de un proyecto que reglamente la transferencia electrónica de los títulosvalores electrónicos, en especial de los documentos de transporte. Es precisamente mediante su informe sobre la labor realizada en el $27^{\circ}$ periodo de sesiones realizado en Nueva York en el año de 1994, cuando el GT-IV aprueba la recomendación por parte de la comisión para examinar en el futuro lo relativo al "carácter negociable o transferible de los derechos sobre mercancías en un medio computarizado". Asimismo se "sugirió la conveniencia de aplicar un criterio más amplio para incluir en cualquier labor futura el carácter negociable de los derechos sobre valores", sin embargo, tal sugerencia fue objetada en razón del "alto grado de regulación en el plano nacional" que dificultaría establecer uniformidad en esa materia. Por último, se sugirió que "se examinaran las cuestiones jurídicas que surgían en el contexto de las relaciones entre Ios usuarios del EDI y los encargados de prestar servicios". ${ }^{6}$

Al año siguiente, en el $28^{\circ}$ periodo de sesiones se aprobaron los artículos 1 y 3 al 11 de la Ley

\footnotetext{
6 Documento A/49/17 Asamblea General. $49^{\circ}$ periodo de sesiones. Suplemento número 17. Informe de la CNUDMI sobre su $27^{\circ}$ periodo de sesiones 31 de mayo a 17 de junio de 1994, párrafo 201. Recuperado de http://daccess-dds-ny.un.org/doc/UNDOC/GEN/N94/287/58/PDF/ N9428758.pdf?OpenElement
} 
Modelo, pidiendo la CNUDMI que se elaborara un estudio sobre los antecedentes de la negociabilidad y transferibilidad de los documentos de transporte mediante EDI, principalmente en el transporte marítimo, y en concreto sobre "la problemática de los conocimientos de embarque transferibles en el entorno electrónico". Será en el $30^{\circ}$ periodo de sesiones en el que queda aprobado el proyecto que reconoció la transmisión de datos electrónicos con la emisión de un recibo de las mercancías, la comunicación de instrucciones al porteador y la transferencia o negociación de las mercancías. ${ }^{8}$ En el $33^{\circ}$ periodo de sesiones nuevamente se hace la sugerencia de llevar a cabo una "desmaterialización de los documentos que confieren título de propiedad, particularmente en la industria del transporte"; es decir, se plantea la viabilidad de establecer un marco jurídico uniforme que sustituya el conocimiento de embarque en soporte papel por el mensaje electrónico aunque la opinión fue que también se podía extender a otros medios de transporte y no únicamente al marítimo. $^{9}$

7 Documento A/50/17 Asamblea General. $50^{\circ}$ periodo de sesiones. Suplemento número 17 . Informe de la CNUDMI sobre su $28^{\circ}$ periodo de sesiones 2 de mayo a 26 de mayo de 1995. Recuperado de http://daccess-dds-ny.un.org/doc/UNDOC/GEN/N95/273/26/IMG/ N9527326. pdf?OpenElement

8 Documento A/52/17 Asamblea General. $52^{\circ}$ periodo de sesiones. Suplemento número 17. Informe de la CNUDMI sobre su $30^{\circ}$ periodo de sesiones 12 de mayo a 30 de mayo de 1997. Recuperado de http:// daccess-dds-ny.un.org/doc/UNDOC/GEN/V97/251/91/IMG/V9725191. pdf?OpenElement.

9 Documento A/55/17 Asamblea General. 55 periodo de sesiones. Suplemento número 17 . Informe de la CNUDMI sobre su $28^{\circ}$ periodo de sesiones 12 de junio a 7 de julio de 2000, párrafo 386. Recuperado de http://daccess-dds-ny.un.org/doc/UNDOC/GEN/N00/644/29/IMG/ N0064429.pdf?OpenElement
De esta manera, cobra relevancia la nota de la Secretaría bajo el documento denominado "Posible futura misión sobre el comercio electrónico. Transferencia de derechos sobre bienes corporales y otros derechos". Documento compuesto de dos capítulos, en el cual se realizó un estudio previo sobre las cuestiones jurídicas relacionadas con el uso de medios de comunicación electrónicos que transmiten o crean derechos sobre bienes corporales u otros derechos, así como un apartado referente a las "iniciativas internacionales sobre la transferencia de derechos por medios electrónicos". ${ }^{10}$ Es en el $44^{\circ}$ periodo de sesiones, donde la CNUDMI le encomienda al GT-IV que lleve a cabo actividades relativas al documento electrónico transferible con la finalidad de promover las comunicaciones electrónicas en el comercio internacional y, en especial, en la aplicación de las RR. Asimismo, se recalcó la importancia de desarrollar el comercio electrónico por medio de dispositivos móviles con las correspondientes reglamentaciones sobre protección al consumidor y a la protección de datos personales. ${ }^{11}$

Asimismo, han sido de gran importancia los propios informes del GT-IV, en especial, el informe relativo al $40^{\circ}$ periodo de sesiones celebrado en Viena del 14 al 18 de octubre de 2002, en el cual se señaló que era necesario especificar las

10 Documento A/CN.9/WG.IV/WP.90 Asamblea General. Grupo de Trabajo sobre Comercio Electrónico. Recuperado de http://daccessdds-ny.un.org/doc/UNDOC/LTD/V00/604/04/PDF/V0060404. pdf?OpenElement

11 Documento A/66/17 Asamblea General. 66 periodo de sesiones. Suplemento número 17 . Informe de la CNUDMI sobre su $44^{\circ}$ periodo de sesiones 27 de junio a 8 de julio de 2011, párrafo 238. Recuperado de http://daccess-dds-ny.un.org/doc/UNDOC/GEN/V13/836/48/PDF/ V1383648.pdf?OpenElement 
definiciones de los conceptos; "escrito", "firma" y "documento" en los instrumentos internacionales para no considerarlos como un obstáculo jurídico en el desarrollo del comercio electrónico. ${ }^{12}$ Pero es mediante su informe del $45^{\circ}$ periodo de sesiones en el cual se tiene como tópico central los "documentos electrónicos transferibles" (transferable records). Documento en el que se discute la problemática jurídica, su equivalencia funcional y la neutralidad de los medios tecnológicos, así como la equivalencia funcional de la "singularidad y de la "posesión". Dentro de los problemas jurídicos se abordó el relativo a la transferencia del documento electrónico con intervención de un tercero debiéndose realizar la distinción entre transferibilidad y negociabilidad, este último abarcando la protección de terceros. Se retomó la característica de singularidad de los títulos-valor en papel, característica que también deberían contar los documentos electrónicos, mediante el concepto de derecho de control del documento electrónico negociable por medio de la equivalencia funcional de la "singularidad y de control". ${ }^{13}$

Sin embargo, es hasta el $47^{\circ}$ periodo de sesiones celebrado en mayo de 2013 , en el que se discutieron los proyectos de discusión relativos al empleo de documentos electrónicos transfe-

12 Documento A/CN.9/527 Asamblea General. Informe del GT-IV (comercio electrónico) acerca de la labor de su $40^{\circ}$ periodo de sesiones en Viena 14 al 18 de octubre de 2002.Recuperado de http://daccess-dds-ny.un.org/doc/UNDOC/GEN/V02/593/97/PDF/ V0259397.pdf?OpenElement

13 Documento A/CN.9/737 Asamblea General. Informe del GT-IV (comercio electrónico) acerca de la labor de su $45^{\circ}$ periodo de sesiones en Viena 10 al 14 de octubre de 2011.Recuperado de http:// daccess-dds-ny.un.org/doc/UNDOC/GEN/V11/867/58/PDF/V1186758. pdf?OpenElement ribles, confirmándose la aplicación de los principios de "equivalencia funcional" y "neutralidad" en los medios electrónicos pero sin tratar cuestiones de derecho sustantivo. Entre los muchos temas a discutir, se cuestionó la definición de “documento electrónico transferible", adoptándose como proyecto de definición como aquel "documento utilizado en un entorno electrónico mediante cuya transferencia se puede transferir el derecho a cumplir una obligación incorporado en él". ${ }^{14}$ Aunado a lo anterior, se hizo hincapié en la continuación de la armonización de aquellas normas que posibilitaban el empleo de documentos electrónicos transferibles y de las transacciones electrónicas.

En diciembre de ese mismo año, se celebró el $48^{\circ}$ periodo de sesiones en el que nuevamente se sometió a discusión el proyecto de disposiciones relativas a los documentos electrónicos transferibles. En esta nueva reunión, con respecto a la definición del "documento electrónico transferible" se sugirió que "transferir el derecho a exigir el cumplimiento de la obligación" abarcaba solamente una de sus funciones. Por lo cual también era necesario hacer mención que entre otras funciones se debía considerar: "el de dar fe de la obligación determinando quien tenía derecho a exigir su cumplimiento", es decir, el tenedor. Asimismo, se propuso que la definición hiciera referencia a tres funciones fundamentales: transferibilidad, titularidad de

14 Documento A/CN.9/768 Asamblea General. Informe del GT-IV (comercio electrónico) sobre la labor realizada en su $47^{\circ}$ periodo de sesiones en Nueva York 13 al 17 de mayo de 2013. Recuperado de http://daccess-dds-ny.un.org/doc/UNDOC/GEN/V13/836/48/PDF/ V1383648.pdf?OpenElement 
Ios bienes y el derecho a exigir el cumplimiento de la obligación. ${ }^{15}$

Por último, en la más reciente sesión (49), que ha sido celebrada en Nueva York del 28 de abril al 2 de mayo de 2014, se subraya el debate a los artículos relativos a los términos de "original", "singularidad" e "integridad", ${ }^{16}$ así como establecer la equivalencia funcional del concepto de posesión consignado en el proyecto del artículo 18 y la discusión sobre el endoso o transmisión del documento electrónico transferible. De esta manera la CNUDMI ha llevado a cabo trabajos preparatorios que impulsan los principios de "equivalencia funcional" principalmente encaminados a la posesión y a los derechos de los tenedores del documento en soporte papel y electrónico, así como el principio de "unicidad o singularidad" y la "transferencia del control" como equivalente de posesión.

Por tanto, uno de los principales problemas que se ha discutido sobre los documentos de transporte electrónicos, es el relativo a la unicidad, derivado de la "posibilidad y facilidad" de copiar

15 Documento A/CN.9/797 Asamblea General. Informe del GT-IV (comercio electrónico) sobre la labor realizada en su $48^{\circ}$ periodo de sesiones en Viena 9 al 13 de diciembre de 2013. Recuperado de http://daccess-dds-ny.un.org/doc/UNDOC/GEN/V13/836/48/PDF/ V1383648.pdf?OpenElement

16 Documento A/CN.9/804 Asamblea General. Informe del GT-IV (comercio electrónico) sobre la labor realizada en su $49^{\circ}$ periodo de sesiones en Nueva York, 28 de abril a 2 de mayo de 2014. Recuperado de http://daccess-dds-ny.un.org/doc/UNDOC/GEN/V14/030/54/PDF/ V1403054.pdf?OpenElement También véase: Documento A/CN.9/ WG.IV/WP.127 Asamblea General. Programa provisional del GT-IV (comercio electrónico) sobre la labor realizada en su $49^{\circ}$ periodo de sesiones en Nueva York 28 de abril al 2 de mayo de 2014. Recuperado de http://daccess-dds-ny.un.org/doc/UNDOC/LTD/V14/007/47/PDF/ V1400747.pdf?OpenElement los documentos electrónicos sin poder diferenciar del propio documento original y de sus copias. Y precisamente, este problema se incrementa con el uso de documentos electrónicos de carácter cambiario como el conocimiento de embarque. Cabe mencionar que esta figura no tiene relación con el "de control o ius variandi" que se ejerce sobre las mercancías, sino es un concepto que se ha introducido por la legislación estadounidense mediante el que se establece una "equivalencia funcional" de la posesión del documento electrónico con la finalidad de asegurar su transmisión.

Precisamente, como en ocasiones anteriores se había comentado, en los últimos años el GT-IV se ha abocado a plantear por medio de diversas sesiones los proyectos de disposición relativos a los documentos electrónicos transferibles con el propósito de promover las comunicaciones electrónicas en el comercio internacional y, en especial, en la aplicación de las RR. De esta manera, con el esquema de una ley-guía, el propio GT-IV ha comenzado a discutir principalmente aquellas cuestiones jurídicas que se plantean en la creación, utilización y transferencia de los documentos electrónicos. Así tenemos que bajo una misma denominación "documentos electrónicos transferibles", se hace referencia a aquellos documentos transferibles de carácter negociable o no negociable, como el pagaré, el cheque, la letra de cambio y los certificados de depósito. Asimismo, se hará referencia a los documentos de titularidad en los que encontramos los documentos de transporte, resguardos de almacén y de muelle, las órdenes de entrega de mercancía y los conocimientos de embar- 
que. Por tanto, partiendo de las características del documento transferible en soporte papel, encontramos cuatro principales problemas jurídicos para resolver: ${ }^{17}$

a. la "unicidad y la garantía de singularidad",

b. la “posesión material del documento electrónico",

c. la "transferencia de los derechos mediante la entrega" $y$,

d. la "identificación y autenticación del tenedor".

El primero de los problemas radica en establecer un ejemplar único (original) y que las siguientes copias sean identificadas como tal; es decir, establecer los mecanismos para identificar la reproducción no autorizada de un documento electrónico con la finalidad de diferenciarlo del original. Una problemática muy importante para resolver, pues se contrapone a la incorporación de los títulos-valores, ya que solo puede existir un derecho incorporado en un único documento. Por tanto, se debe garantizar que un solo acreedor pueda ejercitar el derecho incorporado en el documento electrónico.

Ahora bien, este primer problema difiere del requisito de conservación del documento electrónico en su forma original, lo cual se encuentra

17 Problemas que son explicados en el Documento A/CN.9/WG.IV/ WP.115 Asamblea General. Cuestiones jurídicas relacionadas con el uso de documentos electrónicos transferibles. GT-IV (comercio electrónico) sobre la labor realizada en su $45^{\circ}$ periodo de sesiones en Viena 10 al 14 de octubre de 2011. Recuperado de http:// daccess-dds-ny.un.org/doc/UNDOC/LTD/V11/855/67/PDF/V1185567. pdf?OpenElement reglamentado en el artículo 8 de la Ley Modelo, así como en el párrafo cuarto del artículo 9 de la ECC. Por tanto, la unicidad y la garantía de singularidad consiste en que el documento electrónico sea único y que frente a su reproducción o duplicado sea claramente identificado como tal. No obstante, las RR no han podido señalar cuál y cómo será el procedimiento para garantizar la singularidad, pues si bien el artículo 9 señala la necesidad de "observar ciertos procedimientos" principalmente sobre “... las medidas para asegurar que el documento electrónico de transporte negociable emitido conserve su integridad". De esta manera, la transferencia del "derecho de control o ius variandi" en los documentos electrónicos que regulan las reglas debe efectuarse conforme a los procedimientos que las partes previamente pactaron en el contrato de transporte en el momento de acordar el uso del documento de transporte electrónico remitiendo al primer párrafo del artículo 9.

Con lo cual, las RR únicamente se limitan a señalar la necesidad de un procedimiento previamente establecido en el contrato de transporte, así como el método para la emisión y transferencia del documento y la manera en que se comprobará su entrega y confirmación al tenedor. Asimismo, coincidimos con la crítica que hace Baena (2012, p. 44) en el sentido de conocer cuál es la manera en que se rescata un documento electrónico, pues ni las propias RR lo señalan, lo cual implica un inconveniente material sobre la manera como se "restituye" o se "rescata" el documento electrónico. Por otro lado, la ECC también hace hincapié en la necesidad de reconocer la garantía de singularidad, 
pues esta excluye del ámbito de aplicación a los documentos electrónicos transferibles.

Pero desde el punto de vista tecnológico, ya existen algunos medios que permiten que un documento electrónico no pueda copiarse y que pueda transferirse. Estas herramientas son: el identificador digital de un objeto electrónico (DOI) y la gestión de los derechos de acceso digital a sus servicios (DRM). Sin embargo, el problema de fondo es que el documento electrónico no pueda ser copiado, sino por el contrario, al ser copiado pueda identificarse fehacientemente cuál es el ejemplar original en que se ha consignado el derecho incorporado, identificando además al titular o tenedor del documento electrónico transferible. Para ello, el propio GT-IV ha propuesto el concepto “ejemplar fehaciente", el cual se logra mediante la designación de un sistema de información seguro y específico y de un contenido verificable o de un emplazamiento. Lo anterior se da gracias a un modelo de registro seguro y específico inalterable con la intervención de un tercero como administrador del registro, en donde este podrá emitir el documento electrónico transferible previa solicitud del emisor. Sirve de ejemplo, la regulación que establece el artículo 862 del Código de Comercio de la República de Corea, y su Decreto Presidencial del 4 de agosto de 2008, así como el artículo 35 de las RR.

Por otra parte, debe considerarse que los documentos transferibles en soporte papel no siempre otorgan una garantía de singularidad debido a la falsificación de documentos que llegan a ser considerados como originales. Por ello, "puede no resultar posible encontrar una sola definición legislativa de singularidad"18 aunque esta pudiera ser factible tecnológicamente en los documentos electrónicos (singularidad técnica) al concebir un documento electrónico que no pudiese copiarse y, precisamente, mediante la designación de un ejemplar fehaciente a través del registro. Ahora bien, no únicamente el sistema de registro seguro e inalterable puede garantizar la singularidad, ya que otras legislaciones también han establecido un sistema de truncamiento o compensación electrónico, suprimiendo de esta manera el uso del papel. La ley de Compensación de Cheques del Siglo XXI de Estados Unidos (Check Clearing for the 21st Century Act) o simplemente conocido como "check 21" contempla una compensación bancaria electrónica de cheques mediante la creación de un título negociable denominado cheque sustituto, el cual reemplaza al de papel teniendo una equivalencia funcional para todos los fines. Es decir, se crea una imagen de reemplazo del cheque original que es destruido por el banco que lo generó. Esta imagen será la que se utilizará durante todo el procedimiento compensatorio. El banco lo conservará al menos siete años, teniendo el cliente la posibilidad de obtener una imagen de cheque sustituto en línea. La sección 5 de esta ley establece que la institución bancaria garantiza a las partes interesadas que no se presentará para su cobro el cheque

\footnotetext{
18 Documento A/CN.9/WG.IV/WP.118 Asamblea General. Cuestiones jurídicas relacionadas con el uso de documentos electrónicos transferibles. GT-IV (comercio electrónico) sobre la labor realizada en su $46^{\circ}$ periodo de sesiones en Viena 29 de octubre a 2 de noviembre de 2012. Recuperado de http://www.uncitral.org/pdf/spanish/ workinggroups/wg_iv/46th_WG_IV/wp_118_s.pdf
} 
original ni el sustituto evitando que se realice el cobro dos veces.

De este país, debemos también destacar la sección 9-105 del Código de Comercio Uniforme (más adelante UCC) ${ }^{19}$ y la sección 11 de la Ley Uniforme de Operaciones Electrónicas (más adelante ETAct) ${ }^{20}$ en las cuales se considera un sistema de registro para el uso de títulos transferibles en soporte electrónico. Por otra parte, merece mención especial la regulación sobre los documentos electrónicos transferibles en la legislación colombiana mediante la Ley 962 de 8 de julio de 2005, que en su artículo 26 contempla la factura electrónica, ${ }^{21}$ documento estimado como un título negociable, el cual es emitido y transmitido en el momento de llevar a cabo el descuento de facturas, de conformidad con el contenido de la Ley 1231 de 17 de julio de $2008 .{ }^{22}$

Ahora bien, las menciones a las legislaciones anteriores corresponden al sistema de registro por ser el más utilizado en la práctica. Sin embargo, se ha desarrollado un segundo sistema

19 Recuperado de http://www.law.cornell.edu/ucc/9

20 Recuperado de http://www.austlii.edu.au/au/legis/cth/consol_act/ eta1999256/s11.html

21 Recuperado de http://www.secretariasenado.gov.co/senado/basedoc/ ley_0962 2005.html. Puede consultarse el Documento A/CN.9/ WG.IV/WP.119 Asamblea General. Cuestiones jurídicas relacionadas con el uso de documentos electrónicos transferibles. Propuesta de los Gobiernos de Colombia, España y los Estados Unidos. GT-IV (comercio electrónico) sobre la labor realizada en su $46^{\circ}$ periodo de sesiones en Viena 29 de octubre a 2 de noviembre de 2012 Recuperado de http://www.uncitral.org/pdf/spanish/workinggroups/ wg_iv/46th_WG_IV/wp_119_s.pdf

22 Recuperado de http://actualicese.com/normatividad/2008/07/17/ley1231-de-17-07-2008/ basado en el uso de símbolos electrónicos o tokens incorporados en el documento electrónico transferible, denominado como "sistema de símbolos" (token system). La cualidad de este sistema consiste en identificar mediante un software el documento original como un único ejemplar original del documento para posteriormente poder transferirlo. Al igual que en el sistema de registro, se requiere de la intervención de un tercero. ${ }^{23}$ Por su parte, el GT-IV ha elaborado el proyecto del artículo 13 denominado "singularidad de un documento electrónico" mediante el cual señala que para conseguir tal característica deberá utilizar un "método fiable" consistente en garantizar que el documento electrónico transferible no pueda ser reproducido y se designe un ejemplar fehaciente. De esta manera queda patentizada que la singularidad tiene como finalidad dar derecho a exigir el cumplimiento de la obligación a un solo tenedor del documento electrónico transferible. ${ }^{24}$

Sin embargo, en su más reciente periodo de sesiones $\left(49^{\circ}\right)$ celebrado en Nueva York entre el 28 de abril al 2 de mayo de 2014, se ha adicionado un tercer párrafo al proyecto del artículo 11 relativo a la garantía de singularidad, el grado de fiabilidad del documento electrónico

23 Documento A/CN.9/WG.IV/WP.116 Asamblea General. Aspectos Jurídicos del comercio electrónico. Propuesta del Gobierno de España. GT-IV (comercio electrónico) sobre la labor realizada en su $45^{\circ}$ periodo de sesiones en Viena, 10 de octubre a 14 de octubre de 2011. Recuperado de http://daccess-dds-ny.un.org/doc/UNDOC/LTD/ V11/853/13/PDF/V1185313.pdf?OpenElement

Documento A/CN.9/WG.IV/WP.122 Asamblea General. Proyectos de disposición relativos a los documentos electrónicos transferibles. GTIV (comercio electrónico) sobre la labor realizada en su $47^{\circ}$ periodo de sesiones en Nueva York, 13 a 17 de mayo de 2013. Recuperado de http://daccess-dds-ny.un.org/doc/UNDOC/LTD/V13/813/13/PDF/ V1381313.pdf?OpenElement 
transferible. Este grado de fiabilidad se: “... determinará teniendo en cuenta la finalidad para la que se generó la información contenida en el documento electrónico transferible, así como todas las circunstancias del caso". ${ }^{25}$ Pero se criticó la inclusión de una norma de "fiabilidad general” debido a que: “... podría obstaculizar el empleo de documentos electrónicos transferibles, dado que las consecuencias jurídicas del incumplimiento de esas normas no estaban claras...” agregando también que: “... no era necesario contar con una norma de fiabilidad general, puesto que cada uno de los proyectos de artículos en los que figurara una norma de fiabilidad debería contener una disposición específica para ese contexto". ${ }^{26}$

Como segundo problema del documento transferible que viene de la mano con la garantía de singularidad está el de la "posesión material del documento electrónico", pues, es bajo la tenencia del documento que incorpora el derecho documentado, el cual será necesario para el ejercicio de este según la doctrina de los títulosvalores, se traduce en los rasgos de la incorporación y legitimación. En el ámbito electrónico esta característica se convierte en un reto físico, principalmente para garantizar la existencia de

25 Documento A/CN.9/WG.IV/WP.128 Asamblea General. Proyecto de disposiciones sobre los documentos electrónicos transferibles. GT-IV (comercio electrónico) sobre la labor realizada en su $49^{\circ}$ periodo de sesiones en Nueva York, 28 de abril a 2 de mayo de 2014. Recuperado de http://daccess-dds-ny.un.org/doc/UNDOC/LTD/V14/010/63/PDF/ V1401063.pdf?OpenElement

26 Documento A/CN.9/804 Asamblea General. Informe del GT-IV (comercio electrónico) sobre la labor realizada en su $49^{\circ}$ periodo de sesiones en Nueva York, 28 de abril a 2 de mayo de 2014. Recuperado de http://daccess-dds-ny.un.org/doc/UNDOC/GEN/V14/030/54/PDF/ V1403054.pdf?OpenElement un único documento transferible de manera funcional, equivalente a la posesión material con lo cual se ha acuñado el concepto de "control del documento electrónico" como un equivalente a la posesión. De esta manera, la transferencia del "control del documento electrónico" Ilega a equipararse a la transferencia de la posesión, es decir, a la entrega del documento.

El GT-IV ha implementado en el proyecto de disposiciones sobre los documentos electrónicos transferibles el concepto de "control" y "transferencia de control" bajo los artículos 10, 11 y 17. La redacción de estos artículos se hizo de manera neutral buscando no producir complicaciones desde el punto de vista tecnológico, aplicándose, además, los requisitos de autenticidad del documento y de las firmas, la originalidad e integridad del documento, así como el poder identificar al tenedor del documento electrónico transferible. Es de resaltar que el proyecto del artículo 17 es similar al artículo 7-106 denominado "Control of electronic document of title" del UCC. ${ }^{27}$

Aunque en el más reciente proyecto de redacción llevado a cabo en la $49^{\circ}$ sesión, fueron posicionados bajo los artículos 18 y 20, añadiéndose un artículo 19 relativo a la "fiabilidad del método para determinar el control". El proyecto del artículo 18 se agrega un segundo párrafo estableciendo que el "documento electrónico transferible estará sujeto a control desde el momento de su emisión hasta que quede privado

27 Recuperado de http://www.law.cornell.edu/ucc/7/7-106 
de su validez o eficacia". ${ }^{28}$ Por su parte, las RR mediante el apartado 9, correspondiente al artículo 1 establece una equivalencia funcional entre la posesión física del documento de transporte en papel y el "control" respecto al documento de transporte en soporte electrónico. Asimismo, el apartado 22 de ese mismo artículo, indica principalmente que: "por transferencia de un documento electrónico de transporte negociable se entenderá la transferencia del control exclusivo sobre el documento".

Precisamente, respecto al uso de los documentos de transporte en las RR, la legitimación del tenedor para poder recibir las mercancías estará a expensas de que se realicen los siguientes actos: a) la entrega del documento de transporte al porteador o al tratarse de un documento a la orden, que el tenedor de este se encuentre identificado como la persona a la que debe ser endosado el documento; b) previa demostración del carácter de tenedor del documento electrónico podrá solicitar la entrega de la mercancía, en caso de que no demuestre su carácter de tenedor, el porteador podrá denegar su entrega.

Sin embargo, cabe preguntarse, ¿quién asume el carácter de tenedor? Para efectos de las RR, el artículo 1, el cual fue estructurado como un "diccionario tipo de términos" de la propia Convención, en su apartado señalado como número 10, define lo que deberá entenderse como tene-

28 Documento A/CN.9/WG.IV/WP.128/Add.1 Asamblea General. Proyecto de disposiciones sobre los documentos electrónicos transferibles. Adición. GT-IV (comercio electrónico) sobre la labor realizada en su $49^{\circ}$ periodo de sesiones en Nueva York, 28 de abril a 2 de mayo de 2014. Recuperado de http://daccess-dds-ny.un.org/doc/ UNDOC/LTD/V14/011/61/PDF/V1401161.pdf?OpenElement dor. Por último, la posición jurídica que tendrá el tenedor del documento de transporte dependerá de la relación jurídica con el contrato de transporte, según las hipótesis que establece el artículo 58. Así, la responsabilidad del tenedor dependerá de que sea o no titular del documento y que además deba ejercitar algún derecho que se derive del contrato de transporte.

Como ya se destacó anteriormente, el "control (posesión) del documento electrónico" llega a ser satisfecho, principalmente mediante un sistema de registro con la intervención de un tercero. Lo que nos conduce establecer el problema relativo a la "identificación y autenticación del tenedor". Pero, para identificar a la persona en favor de la cual se emitió o transfirió el documento, se establecen tres hipótesis: ${ }^{29}$

1. Identificación de la persona que ejerce el control en el propio documento electrónico transferible. Se basa en identificar a la persona que ejercerá el control sobre el documento electrónico, el tenedor, la cual aparece en el propio documento; por lo que los cambios de titularidad del tenedor son plasmados directamente en el documento. Para ello es indis-

Véase Documento A/CN.9/WG.IV/WP.115 anteriormente descrito. Por otra parte, este mismo documento señala que se han desarrollado proyectos que han trabajado sistemas electrónicos en los que se puede transmitir la posesión de las mercancías mientras la carga se encuentra en tránsito, a través de documentos en soporte en papel el cual es sustituido por el documento electrónico. Entre los que se encuentran, el ya anteriormente citado Sistema Bolero, la plataforma de intercambio ESS-Databridge y el sistema de registro KTNET. El primero de ellos consiste en un registro de carácter electrónico sobre los conocimientos de embarque a través del libro de registro Bolero, en el que las partes quedan adheridas a la condiciones sobre transmisibilidad y validez de los mensajes de datos electrónicos. El sistema KTNET funciona a través del registro de los documentos en soporte papel y electrónicos. A su vez, el sistema ESS-Databridge únicamente limita el acceso del documento electrónico. 
pensable que el sistema lleve a cabo un estricto control sobre el documento electrónico transferible y, principalmente, del registro de transferencias de control. Además es sumamente importante garantizar la existencia del "ejemplar fehaciente".

2. Identificación de la persona que ejerce el control a través del modelo de registro. Bajo esta hipótesis, se identifica al tenedor del documento que ha sido consignado previamente en un registro distinto a cargo de un tercero ajeno, quien registrará el documento para verificar también su integridad. Se deja a un lado la singularidad del documento ya que lo que importa es que en el registro se mencione quién es la persona que ejerce el control sobre el documento electrónico transferible para que cualquier individuo que obtenga una copia del documento pueda identificar a su titular a través del propio registro.

3. Identificación de la persona que ejerce el control por medio de un sistema de acceso exclusivo. Este tipo de identificación se basa en almacenar y reconocer al ejemplar fehaciente del documento electrónico transferible en un sistema informativo creado especialmente para él, protegido por controles de seguridad indicando al tenedor del documento electrónico transferible.

Ahora bien, respecto al problema de la "transferencia de los derechos mediante la entrega" se realiza mediante la transmisión del control sobre el documento electrónico transferible, mediante un equivalente funcional al endoso.
Para ello se ha utilizado como ejemplo el artículo 7-501 b) denominado "Form of negotiation and requirements of due negotiation" del UCC, el cual reglamenta la transferencia de estos documentos estableciendo una equivalencia funcional del endoso. ${ }^{30}$ Sin embargo, las RR señalan en el segundo párrafo del artículo 57 que podrán transferirse los derechos incorporados en el documento mediante la transferencia del documento de transporte electrónico de conformidad con los procedimientos señalados en el párrafo primero del artículo 9, de ese mismo ordenamiento, pero sin mencionar concretamente el equivalente funcional del endoso.

\section{CONCLUSIONES}

Las Reglas de Rotterdam representan desde mi punto de vista un parteaguas en la armonización y unificación de la reglamentación del contrato de transporte marítimo y, en especial, a la documentación mediante la consumación del documento de transporte marítimo como un título representativo de las mercancías.

Esta regulación no contempla solamente el soporte tradicional del papel sino incluye el medio electrónico bajo la perspectiva del fundamento rector en la contratación electrónica: la equivalencia funcional. Principio que al ser aplicado a la teoría cartular genera algunos cuestionamientos.

Estos cuestionamientos consisten en garantizar la existencia de un documento electrónico único

30 Recuperado de http://www.law.cornell.edu/ucc/7/7-501 
y original, capaz de diferenciarse de las copias que se llegaran a generar a partir de él, así como su posesión material mediante la identificación de su tenedor y, en especial, la transferencia del derecho documentado en soporte electrónico. Ante tales cuestionamientos jurídicos, el GT-IV advierte la aplicación de manera universal del principio de equivalencia funcional acuñando los conceptos de "singularidad de un documento electrónico" consistente en garantizar la originalidad del documento electrónico designándolo como un ejemplar fehaciente; así como el concepto de "control y transferencia de control del documento electrónico" como equivalente a la posesión y a su transferencia, ya existiendo además una respuesta tecnológica. Por su parte, las RR contemplan en el artículo 8 que la emisión del control del documento electrónico de transporte surtirá los mismos efectos que la emisión, posesión o transferencia del documento de transporte en soporte electrónico.

\section{Referencias}

Aguirre. F. (2013). Las Reglas de Rotterdam: derecho y política. En Espinosa Calabuig R. (dir.), Las Reglas de Rotterdam sobre Transporte Marítimo. Pros y contras del nuevo convenio. Valencia: I+D+I. Tirant lo Blanch.

Alba, M. (2007). Documentos de transporte y negociabilidad en un entorno electrónico (segunda parte). Revista de Derecho Mercantil, 264-265, 522-523.

Arroyo, I. (2013). Las Reglas de Rotterdam en el derecho español. En Espinosa Calabuig R. (dir.), Las Reglas de Rotterdam sobre Transporte Marítimo. Pros y contras del nuevo convenio. Valencia: I+D+I. Tirant lo Blanch.

Ascarelli, T. (2008). Teoría general de los títulos de crédito [en línea]. Primera edición. Tribunal Superior de Justicia del Distrito Federal. Dirección General de Anales de Jurisprudencia y Boletín Judicial. México. Recuperado de http://biblio.juridicas.unam.mx/libros/libro. htm?l=3117

Baena, P. (2012). La Regulación en las Reglas de Rotterdam de la entrega de las mercancías en caso de haberse emitido un documento de transporte negociable. Anuario de Derecho Marítimo, XXIX.

Devescovi, F. (1991). Titolo di credito e informática. Padova. CEDAM, Le monografie di Contratto e impresa 17.

Declaración de Montevideo contra las Reglas de Rotterdam (2011). Documento disponible íntegramente en la Revista Anuario de Derecho Marítimo XXVIII. Instituto Madrileño de Desarrollo Comunidad de Madrid Consejería de Economía y Hacienda (pp. 687-691).

Emparanza, A. (1994) El transporte marítimo bajo conocimiento de embarque: su régimen jurídico internacional tras la entrada en vigor de las reglas de Hamburgo. En José M. de Eizaguirre; J. J. Álvarez Rubio (coord.), Jornadas sobre Transporte Marítimo Europeo, aspectos mercantiles y jurisdiccionales. El derecho del transporte marítimo internacional. Go- 
bierno Vasco, Departamento de Transportes y Obras Públicas Vitoria-Gasteiz.

Espinosa, R. (2013). Jurisdicción, libertad contractual e intereses de terceros en las Reglas de Rotterdam. En Espinosa Calabuig R. (dir.), Las Reglas de Rotterdam sobre Transporte Marítimo. Pros y Contras del Nuevo Convenio. Valencia: I+D+I. Tirant lo Blanch.

Espinoza, C. S. (1991). De las Reglas de La Haya a las Reglas de Hamburgo: Nuevas formas de transporte marítimo en la ley chilena. Revista Temas de Derecho, IV (1), 36-38.

García, J. (2006). Derecho de títulos-valores: (parte general). Santiago de Compostela: Tórculo Edicións.

Gómez, R. (2009). Documentos y nuevas tecnologías. En Sendín, M. y Gómez, R. (dirs.), Régimen jurídico de los documentos. Aspectos administrativos, civiles, penales y procesales. Estudios de derecho administrativo. Granada: Editorial Colmares.

Gómez, J. (2011). El título valor electrónico, especial referencia a la letra de cambio electrónica y la actuación notarial. Revista La Notaria, 4, 103.

Illescas, R. (2009). Derecho de la contratación electrónica. Madrid: Civitas-Thomson Reuters.

Jiménez, G. (1998). Títulos-valores y Documentos del Transporte. En Madrid Parra, A. (coord.), Derecho uniforme del transporte internacional: cuestiones de actualidad. Madrid: McGraw Hill.

Madrid, A. et al. (1996). Contratación electrónica. En Estudios jurídicos en homenaje al profesor Aurelio Menéndez. Iglesias, J. (coord.). Tomo III: contratos mercantiles, derecho concursal y derecho de la navegación. Madrid: Civitas.

Madrid, A. et al. (1998). Regulación uniforme de Uncitral del uso de medios electrónicos en relación con los contratos de transporte de mercancías. En Madrid Parra, A. (coord.), Derecho uniforme del transporte internacional: cuestiones de actualidad. Madrid: McGraw Hill.

Martín, M. (2000). Nuevas formas de documentación del contrato de transporte: La sustitución del soporte material por la documentación electrónica. RCE. Revista de la Contratación Electrónica, 7, 30.

Muñoz, A. (2012). La autonomía de la voluntad en las Reglas de Rotterdam. Revista de Derecho del Transporte, 9, 16.

Paz-Ares, C. (1996). La desincorporación de los títulos-valor. Revista de Derecho Mercantil, 219, 17.

Pendón, M. (1994). Los títulos representativos de la mercancía. Madrid: Marcial Pons.

Ravina, A. (1982). Los países centroamericanos frente al Convenio de las Naciones Unidas sobre el Transporte Marítimo de Mercancías, 
1978 (Reglas de Hamburgo). Revista Integración Latinoamericana, 7 (65), 31.

Recalde, A. (2010). Documentación del contrato, derecho de control y transferencia de derechos sobre las mercancías. En Emparanza, A. (dir.), Las Reglas de Rotterdam. La regulación del contrato de transporte de mercancías por mar. Manuales Profesionales Mercantil. Madrid: Marcial Pons.

Recalde, A. (1992). El conocimiento del embarque y otros documentos del transporte: función representativa. Madrid Monografías Civitas, 47-4.9

Rico, M. (2014). Los documentos electrónicos transferibles como equivalentes funcionales de los títulos cambiarios. La Ley mercantil. $N^{0} 1$ Sección Contratación mercantil, comercio electrónico y TIC'S.

Sánchez, F. (2010). El contrato de transporte marítimo de mercancías: (Reglas de La Haya-Wisby, Hamburgo y Rotterdam). Navarra: Aranzadi. 